\title{
Cost Control and Optimization of Thermal Power Generation Enterprises by Value Chain Analysis
}

\author{
Jinyu $\operatorname{Tian}^{1}$, Shiyao Wang ${ }^{2, \text { a }}$ \\ ${ }^{1}$ Department of Economics and Management, North China Electric Power University, Baoding, \\ Hebei Province, China, 071003; \\ ${ }^{2}$ Department of Economics and Management, North China Electric Power University, Baoding, \\ Hebei Province, China, 071003. \\ awsynet@126.com, 2513947647@qq.com
}

Keywords: Cost control and optimization; Value chain analysis; Thermal power generation enterprises; New Round of electric power system reform

\begin{abstract}
The New Round of Electric Power System Reform has been identified by National Development and Reform Commission in 2014. Coal-fired power generation plays an important role in China's electric power industry. With the impact of the Reform propulsion and clean energy growing rapidly, the original developments of blocked coal power companies are more challenging than ever. In this paper our research aims to analyzing the raising challenges and cost control of coal-fired power generation enterprises in the new circumstance based on the theory of value chain analysis. Then it comes to the point that enterprise must implement a low-cost strategy, through the fuel, equipment, management and other elements of the cost control and process optimization to achieve the purpose of cost reduction. The study draws the solutions about coal operation chain, equipment maintenance chain and auxiliary operation chain.
\end{abstract}

\section{Introduction}

New Round of electric power system reform has been identified by National Development and Reform Commission in 2014, and in Dec.2014, they announced The Test Method of Shenzhen District Supply and Distributing Electricity, which indicated the New Round of Electric Power System Reform's new stage beginning in Shenzhen. On March 2015, the new leading file of electric power system reform named The State Council of the Peoples' Republic of China's suggestions about diving in reform electric power system is announced. Then, more specific file related to electric power system reform is announced.

With the advent of reformation, the burgeoning of electric power industry is pushed by the fast pace of GDP, reform of electric power system reform and the increase of the amount of electricity generation device etc. The data shows Power generation installed capacity is $1,360,190,000 \mathrm{KW}$ by the end of 2014, which is $8.7 \%$ increase than last year; fired power generation capacity is $915,690,000$ $\mathrm{KW}$ (Coal fired generation is $825,240,000 \mathrm{KW}$, gas fired generation is 55,670,000 KW), make $67.4 \%$ of the total capacity of electricity generation[1]. The new equipment takes 103,500,000 KW, including 47,290,000 KW of fired generation [2]. December 2014, China's thermal power generation capacity is 398 billion KWh, decreased by 1.3\% [3], and decreased for sixth consecutive months. 


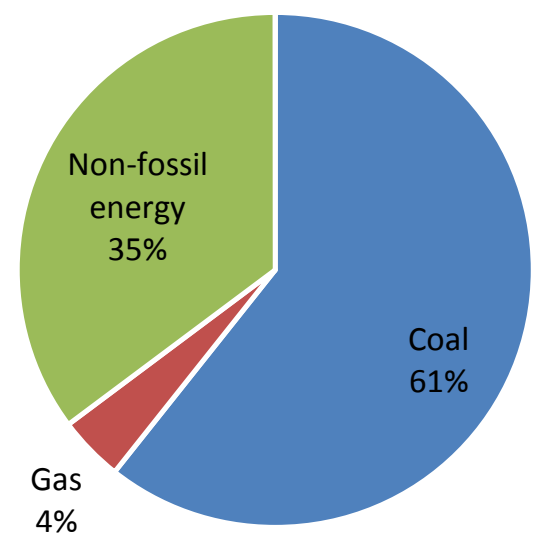

Fig. 12014 Power generation capacity

\section{Method}

We have developed the study by using the methods of literature research and empirical research to analyze the cost control and optimization problems of coal-fired power generation enterprises under the background of the New Reform in China. Combining cost control and optimization theory with the theory of value chain to analysis the empirical enterprise.

\subsection{Cost control and optimization theory}

Cost control theory became mature in 1970s. Variety of cost control methods are proposed, including product life cycle costing, activity-based costing, strategic cost control. Among them, the concept of strategic cost management proposed by the British scholar Simon in 1980s, has been developed by Professor Michael Porter, Harvard University business school, and formed the value chain theory.

This paper is focus on the optimization, emphasis on process optimization improve through the process of production. The author is dedicating to achieve the best result within the constraint of limited resources. By reducing costs, enterprises could continue to develop and improve the business process, in order to maintain their competitive advantages.

\subsection{Theory of value chain analysis}

The purpose of the value chain analysis is to analyze the value activities in the business activities, to find out the problems, and to reinforce the competitive advantage of the enterprises through the control and optimization.

(1)The value chain

The value chain is firstly introduced in 1985 in the Competitive Advantage by Professor Michael Porter from Harvard Business University. Porter's value chain can be split into activities according to corporate strategy, so as to understanding of the cost behavior, differentiation and analysis of potential incentives [4]. In order to implement the activities that have important strategic significance, the firm will gain the competitive advantage to lower the cost or achieve a better quality.

It is widely accepted that company in same field may have the same competitive advantage, nevertheless there exist larger differences in the process of manufacturing operations between different competitors, the process of creating value to a buyer's market, the production line constitute elements, sales channels, sales targets are different in value chain for future product out sale brought different results [5]. Whilst the activities in the value chain are related to one another, the way to change one of the activities can reduce the total cost of the two. It is possible to raise the cost of an activity not only to reduce the cost of another activity, but also to reduce the total cost of the project [4]. Research in Porter's analysis of value chain has shown that, the value chain of enterprise was divided into internal value chain and external value chain. Internal value chain enterprise in the 
production process, different segments of the value creation can constitute the internal value chain system [6]. In addition, external value chain enterprise in formation and contact suppliers, distributors and consumers of the role of the external value chain system.

(2)Value chain analysis

Value chain analysis is a theory which produced on the basis of the theory of value chain analysis tools. It regarded competitive advantage as a tool for determining. We have developed this study to provide a reference for the enterprise development strategy. Value chain analysis is the overall analysis of the value chain, including the external horizontal, vertical value chain and internal value chain analysis. After the horizontal analysis of the value chain, the enterprise can find its competitive disadvantage compared with the competitors, and the unreasonable in the upstream and downstream links, so as to take reasonable measures to improve. As for the vertical analysis of the value chain, it can make the enterprise focus on the discovery of the need for suppliers, distributors and other process integration strategy, take appropriate measures to reduce costs and improve competitive advantage. Moreover, the enterprise internal value chain analysis can confirm the value produced in the process of enterprise production operation of specific activities, hence to decide whether to point disadvantage is improved and exclusion with different segments of the input and output for comparison.

The ultimate goal of value chain analysis is to analyze and distinguish whether the activity is added to the enterprise value from the outside and inside of the enterprise, so as to improve or screen the unnecessary stages.

\section{The Results}

Based on these findings, we may conclude that even if fuel costs accounted for about $70 \%$ of the cost of power generation, coal prices mainly impacted by the market not the company's willing. In that case, coal-fired power plants in considering the coal related costs should consider improving the conversion efficiency of coal-fired, reducing coal consumption and reducing the cost of power generation. Depreciation charge in the cost of electricity accounted for about $16 \%-19 \%$, which shows that under the current electricity regulatory and government price restrictions, the thermal power enterprise's production capacity has not been fully utilized. Consequently, in the cost control and optimization analysis of coal-fired power generation enterprises, the specific control and optimization of the enterprise can be implemented in the following two aspects.

\subsection{External longitudinal value chain cost control and optimization point}

Our results suggest that in the vertical value chain, the main key points in the upper and lower reaches of the mutual convergence. In this value chain, the main problems are reflected in the upstream-coal acquisition and processing enterprises on the supply of raw materials for coal-fired power generation enterprises, or the existence problem on price and quantity[7]. It is widely accepted that the development of China's power market requires enterprises to continuously innovate and improve the speed in the changing environment. Results of the study showed that if the coal supply chain can be improved in the environment of countries to stabilize the price of coal, to ensure coal adequate and stable supply, in the process of reduced logistics costs, improve transport capacity, enterprise's cost will be significantly reduced. In such case, the fierce competition in the new electricity reform will not be at a disadvantage.

\subsection{Internal value chain cost control and optimization point}

The findings demonstrate that in the internal value chain, only when main and support production chain and assistant processing chain worked together, can enterprise functions well. Especially with the trend of the New Reform, there will be some influence on the internal value chain.

\section{Discussion}

In this study, we attempt to provide the problem of cost deduction on thermal power enterprise on following 3 aspects. 


\subsection{Fuel}

It could be argued that coal is an important basis for thermal power generation. Primary energy constitutes more than $50 \%$ of the cost of electricity generation, so the price change of primary energy has a significant impact on the cost of thermal power generation enterprises. Currently, coal prices in China tend to be stable in the long term. Governments at all levels to take measures to strengthen the integration of coal, when the new round reform of electric power system strike the thermal power generation enterprises, the control of fuel cost is vital.

\subsection{Equipment}

It must be point out that many power plants ignore the daily maintenance of the equipment, so the cost is higher in the later stage of equipment's overhaul. There is no perfect measure to manage and control, making the cost increased and withdrawing with no excuse, impacting the cost control of power plant. Notwithstanding China's environmental governance related policies, laws and so on are not perfect, but the coal-fired power generation enterprises need to combine their own cost in the long run, and actively improve the technology to improve the efficiency of using coal. In addition, the current power load forecasting technology for coal-fired power generation enterprises still needs to be improved. With the advent of the New Reform in the future, to overcome these limitations, the sale side will be docked with the using side. Facing the competition, if not actively improve the prediction technology, self-developing forecast system to predict their own power generation situation and peers' quantities in the future, bidding strategy with high precision and high precision in technology cannot be proposed, it will be hard to obtain maximum benefit. It will be cast doubt on occupying a dominant position in the market.

\subsection{Management}

Likewise, thermal power generation enterprise management mainly includes human resources management, material procurement management and financial cost management. Human resource cost growth is too fast, and it has become one of the main problems in the cost control of thermal power enterprises, it mainly performance in the following three aspects: First, for the fierce competition of human resources, the demand for high quality talents is increasing, so there is a phenomenon that the human resources supply is less than the demand of the talent market; in the next place, the wage comparison difference and the labor value's self-understanding also make the human cost in the unceasing increase; the last one is due to the constant change of our country's macro control policy, which makes the labor cost increased, and increasing the enterprise's labor cost control.

\section{Conclusion}

As a country with abundant coal but shortage power, Coal-burning Electricity-generating will occupy an important position in electric power industry. Nonetheless, the strict requirements about electric power enterprises such as discharge standard have been issued. Power generation and enterprises whom do not meet the requirements will be eliminated by punitive measures. As a consequence, it is of great significance that government needs paying efforts to achieve the coal enterprises sustainable development. In the present study, we attempt to give a solution for thermal power generation enterprise by using value chain analysis. Facing the New Reform's strategy of building generation competitive market, opening the sell side market, government regulation grid, user buy electricity freely, whilst coal fired electric generation will keep leading the electric power generation in middle term or long term. Even though, it will fall behind other kinds of power generation in cost control. As a way forward, if coal fired generation industrial wants new development in New Reform, they have to improve the efficiency and management skill by reducing the production cost and improving production efficiency and enhancing the competitiveness. Only in this way can the enterprises strive for more power generation and profit to in the future fierce competition in the industry to achieve development in future. 


\section{References}

[1]. Ping Zhang, Steady increase in installed capacity of power generation equipment -- annual report of power generation equipment industry development in 2014[W]. Medium Power News Network. http://www.cpnn.com.cn/zdyw/201502/t20150212_783136.html.(In Chinese)

[2]. National Energy Administration, 2014 total electricity consumption [W]. Website on National Energy Administration.(In Chinese)

[3]. National Bureau of Statistics of People's Republic of China, December in 2014 Standard-Sized Enterprises Producing Value Increased by 7.9\% [W]. Website on National Bureau of Statistics of People’s Republic of China.(In Chinese)

[4]. The State Council of the Peoples' Republic of China's suggestions about diving in reform electric power system [Z].2015(In Chinese)

[5]. Carlyss Y Baldwin, Kim B Clark. Value Chain Management[M]. New York: Professional Books Group, 2000: 28-31

[6]. Michael Porter. Competitive Advantage [M]. New York: AcadeAnc Press. 1984: 31-42

[7]. Dongxiao Niu, Chongming Liu, The strategic cost management of thermal power enterprise value chain [M] Shenyang: Liaoning University Press, 2010: 141-142.(In Chinese) 